This is the final peer-reviewed accepted manuscript of:

M. Placci, G. Marliani, S. Sabioni, G. Gabai, E. Mondo, P. Borghetti, E. De Angelis \& Pier Attilio Accorsi (2019) Natural Horse Boarding Vs Traditional Stable: A Comparison of Hormonal, Hematological and Immunological Parameters, Journal of Applied Animal Welfare Science

The final published version is available online at: https://doi.org/10.1080/10888705.2019.1663737

Rights / License:

The terms and conditions for the reuse of this version of the manuscript are specified in the publishing policy. For all terms of use and more information see the publisher's website. 


\title{
Natural Horse Boarding Vs Traditional Stable: A Comparison of Hormonal, Hematological and Immunological Parameters
}

\author{
M. Placci ${ }^{a}$, G. Marliani a , S. Sabionib ${ }^{\text {}}$, G. Gabaic, E. Mondo ${ }^{\text {a }}$, P. Borghetti ${ }^{d}$, E. De \\ Angelis $^{d}$, and Pier Attilio Accorsi ${ }^{a}$

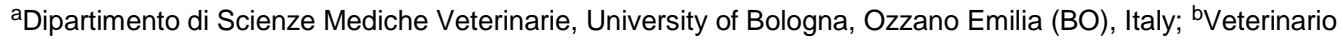

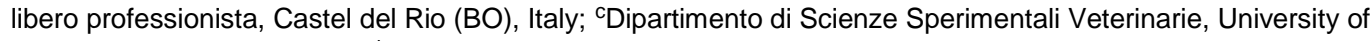 \\ Padova, Legnaro (PD), Italy; ${ }^{\mathrm{d} D e p a r t m e n t ~ o f ~ A n i m a l ~ H e a l t h, ~ U n i v e r s i t y ~ o f ~ P a r m a, ~ P a r m a ~(P R), ~ I t a l y ~}$
}

\begin{abstract}
In the equestrian world, two different types of management can be distinguished: traditional management and natural boarding. The aim of this research was to compare hormonal, hematological and immunological parameters of 47 horses kept in these two different managements. Blood and horsehair of the horses were sampled to determine DHEA (dehydroepiandrosterone) and cortisol concentration through RIA. Moreover, blood count was conducted, and flow cytometry was employed to phenotype lymphocyte subpopulations. Results showed that, in horsehair, DHEA concentration was significantly higher in natural horses, whereas cortisol concentration and cortisol/DEHA ratio significantly lower. These hormonal parameters are used to assess the stress condition and the welfare of animals. The most favorable endocrine framework found in horses kept in natural boarding suggests that this management conveys most with ethological and physiological needs of the species. The research underlines the need of a modification of horses' husbandry systems. For the first time, this study validates the assay of DHEA in horsehair.
\end{abstract}

KEYWORDS

Horses; DHEA; cortisol; lymphocytes; management

\section{Introduction}

The concepts of "welfare" take into account animal body health, feelings, natural life conditions, and behaviors. A condition of good welfare depends on environment, husbandry and human animal care (Ewing, Lay, \& von Borell, 1999; Fraser, 2001; Moberg, 1987). Even if stress and welfare are two different concepts, they both depend on animals' perception of environment and describe their physiological and behavioral responses (Moberg, 2000; Veissier \& Boissy, 2007). Stress responses, such as cortisol release, are commonly used to assess animal welfare. Researches on stress have led to an increasing interest on psychoneuroimmunology (PNI), which studies the interactions among the central nervous system, the endocrine system, and the immune system, in particular under stress conditions (Padgett \& Glaser, 2003).

Nowadays, the interest in animal welfare and the knowledge of equine physical and ethological needs have led to the development of natural horse boarding, which distinguish itself from traditional stables (Bekoff \& Byers, 1988; Mills \& Nankervis, 2001). Horses are grazing herbivores, social animals and preys, who, during their evolution, have developed the escape and group living as principal survival strategies. Current management practices of horses are driven by human requirements and costs limitations but often ignore basic equine needs. In developed countries, most performance and leisure horses are intensively managed. They are predominantly confined and socially isolated in a stable. The traditional management adopts individual stalls and maintains their 
horses in enclosed environments most of the time, because it is easier to control them, their diet, and to catch them and to maintain them clean. From humans' point of view, stalls give protection from weather and a comfortable place where to leave, but horses have a different perception of it. In this condition, they are vulnerable and isolated in a closed place that prevents them to escape and restricts their sensory input to control the presence of predators. Moreover, the animals have few opportunities of socialization with other horses. In this kind of management, horses are usually fed twice or three times per day, using a different feeding from that natural (Strasser, 2005; Van Dierendonck \& Goodwin, 2005). However, the isolation and the restriction of foraging time can lead equines to develop stereotypies and aggressive behaviors (Goodwin, 1999). In a natural environment, horses pass up to $18 \mathrm{~h}$ per day eating, searching and choosing different foodstuffs. For the characteristics of their digestive tract, they should eat small amount of food but continuously. In traditional management, food is provided twice or three times per day and this leads animals to boredom and to the development of pathological conditions, such as colic and gastric ulcers. Another deal is to guarantee to horses the chance of an adequate movement. Horses can travel more than $20 \mathrm{~km}$ per day and the free movement in stimulant open spaces gives them the possibility of developing and strengthening muscles and joints and it helps digestion process, metabolism, circulation, and respiration (Mills \& Nankervis, 2001; Saba, Montagnani, \& Ascione, 2014). The natural boarding of horses tries to fulfill the ethological needs of these animals, keeping them in wide-open spaces and paddocks, letting them to live in herds and giving them the possibility of socializing and of a natural and various feeding. In the traditional management, the equines are shod, and they are ridden using mouthpiece. In addition, during the winter usually, they are clipped and wear blankets. On the contrary, the natural boarding employed the barefoot and, most of the time, horses are ridden without the mouthpieces. In this management, horses are not clipped to favorite the natural mechanisms of thermoregulation (Strasser, 2005).

The aim of this research was to compare hormonal and immunological parameters of sporting horses kept in traditional and natural management. The study has focused on the determination of cortisol and dehydroepiandrosterone (DHEA) levels, and the assay of B-lymphocytes and lymphocyte subpopulations CD4+ and CD8 +. The hypothalamus-pituitary-adrenal (HPA) axis activation is involved in stress and inflammation (Silverman \& Sternberg, 2012), and cortisol and dehydroepiandrosterone (DHEA) are the main players of this neuroendocrine system. Cortisol is the main glucocorticoid hormone, and its secretion is related with various diseases and stress conditions (Ayala et al., 2012). Most information on DHEA derives from human and laboratory rodent studies, while few information is available about the biological role of DHEA in ungulates, in particular, the horse. DHEA is an androgen of adrenal origin, but it is also produced in the gonads and in the brain. In humans, DHEA and its sulfated metabolite (DHEA-S) are the most abundant steroids in the circulation (Clark, Prough, \& Klinge, 2018) and serve as precursors in androgen and estrogens biosynthesis in peripheral tissues (Hill, Dušková, M. \& Stárka, 2015). DHEA has putative antiglucocorticoid effects (Prall \& Muehlenbein, 2018), and measuring cortisol and DHEA and analyzing the cortisol/DHEA ratio allow a more accurate evaluation of the HPA axis activation in stressful or inflammatory situations.

The research has not focalized on ethological observations that other studies apply but has wanted to highlight the influence of different management on physiological parameters, important also to investigate the state of health of animals.

\section{Materials and methods}

\section{Ethical considerations}

The entire study was previously evaluated and approved by Scientific Ethic Committee for Animal Experimentation of Bologna University. The trial was monitored by the responsible of DIMEVET (Department of Veterinary Medical Sciences) for Animal Welfare. 
Table 1. Subjects of the study including in NM (Natural Management) and CM (Conventional Management) groups. $\mathrm{G}=$ Gelding; F = Female; $\mathrm{S}=$ Stallion.

\begin{tabular}{|c|c|c|c|c|}
\hline Breed & Gender & Age (ys) & Type of equestrian activities & Group \\
\hline Italian Saddle Horse & G & 18 & school and trekking & NM \\
\hline Bardigiano & $\mathrm{F}$ & 16 & school and trekking & NM \\
\hline Paint Horse & $\mathrm{F}$ & 6 & school and trekking & NM \\
\hline Quarter Horse X Bardigiano & $\mathrm{F}$ & 8 & school and trekking & NM \\
\hline Quarter Horse & G & 9 & trekking & NM \\
\hline Irish Sport Horse & G & 18 & show jumping - dressage elementary level & NM \\
\hline Thoroughbred & $\mathrm{F}$ & 18 & trekking - dressage elementary level & NM \\
\hline Belgian Warmblood Horse & G & 15 & trekking - dressage elementary level & NM \\
\hline Holsteiner & $\mathrm{F}$ & 7 & show jumping - dressage elementary level & NM \\
\hline Holsteiner & $\mathrm{F}$ & 6 & show jumping - dressage elementary level & NM \\
\hline Westfallien & G & 11 & show jumping - dressage elementary level & NM \\
\hline Italian Saddle Horse & G & 4 & show jumping - dressage elementary level & NM \\
\hline Italian Saddle Horse & $\mathrm{F}$ & 9 & show jumping - dressage elementary level & NM \\
\hline Trakehner & $\mathrm{F}$ & 11 & show jumping - dressage low level - trekking & NM \\
\hline Hannover & $\mathrm{F}$ & 10 & show jumping - dressage medium level - trekking & NM \\
\hline Italian Saddle Horse & G & 17 & show jumping - dressage elementary level & NM \\
\hline Arabian Horse & G & 11 & show jumping - dressage elementary level - endurance $(60-90 \mathrm{~km})$ & NM \\
\hline Belgian Warmblood Horse & $\mathrm{F}$ & 16 & hippotherapy - show jumping - dressage elementary level & NM \\
\hline Italian Saddle Horse & $\mathrm{F}$ & 16 & hippotherapy - show jumping - dressage elementary level & NM \\
\hline Italian Saddle Horse & $\mathrm{F}$ & 26 & hippotherapy - show jumping - dressage elementary level & NM \\
\hline Italian Saddle Horse & $\mathrm{F}$ & 10 & hippotherapy - show jumping - dressage elementary level & NM \\
\hline Italian Saddle Horse & G & 18 & School & $\mathrm{CM}$ \\
\hline Italian Saddle Horse & $\mathrm{F}$ & 6 & show jumping - dressage elementary level & $\mathrm{CM}$ \\
\hline Belgian Warmblood & G & 8 & show jumping - dressage elementary level & $\mathrm{CM}$ \\
\hline Italian Saddle Horse & G & 4 & show jumping - dressage elementary level & $\mathrm{CM}$ \\
\hline Italian Saddle Horse & $\mathrm{F}$ & 4 & show jumping - dressage elementary level & $\mathrm{CM}$ \\
\hline Belgian Warmblood & G & 17 & show jumping - dressage elementary level & $\mathrm{CM}$ \\
\hline Italian Saddle Horse & G & 14 & show jumping - dressage elementary level & $\mathrm{CM}$ \\
\hline Italian Saddle Horse & G & 14 & show jumping - dressage elementary level & $\mathrm{CM}$ \\
\hline Kwpn & G & 18 & show jumping - dressage elementary level & $\mathrm{CM}$ \\
\hline Anglo Arabo Sardo & $\mathrm{F}$ & 18 & School & $\mathrm{CM}$ \\
\hline Ungarian Saddle Horse & G & 11 & show jumping - dressage elementary level - school - trekking & $\mathrm{CM}$ \\
\hline Kwpn & G & 30 & show jumping - dressage elementary level - school & $\mathrm{CM}$ \\
\hline Anglo Arabo Sardo & G & 14 & show jumping - dressage elementary level - school & $\mathrm{CM}$ \\
\hline Italian Saddle Horse & G & 9 & show jumping - dressage elementary level & $\mathrm{CM}$ \\
\hline Italian Saddle Horse & G & 5 & show jumping - dressage elementary level & $\mathrm{CM}$ \\
\hline Italian Saddle Horse & G & 6 & show jumping - dressage elementary level & $\mathrm{CM}$ \\
\hline Italian Saddle Horse & G & 5 & show jumping - dressage elementary level & $\mathrm{CM}$ \\
\hline Italian Saddle Horse & G & 4 & show jumping - dressage elementary level & $\mathrm{CM}$ \\
\hline Italian Saddle Horse & $S$ & 6 & show jumping - dressage elementary level & $\mathrm{CM}$ \\
\hline Italian Saddle Horse & $\mathrm{F}$ & 8 & show jumping - dressage elementary level & $\mathrm{CM}$ \\
\hline Italian Saddle Horse & G & 5 & show jumping - dressage elementary level & $\mathrm{CM}$ \\
\hline Italian Saddle Horse & $\mathrm{F}$ & 7 & show jumping - dressage elementary level & $\mathrm{CM}$ \\
\hline Italian Saddle Horse & G & 4 & show jumping & $\mathrm{CM}$ \\
\hline Arabian Horse & G & 9 & dressage elementary level & $\mathrm{CM}$ \\
\hline Criollo Horse & G & 22 & dressage elementary level & $\mathrm{CM}$ \\
\hline Italian Saddle Horse & $\mathrm{F}$ & 6 & dressage elementary level & $\mathrm{CM}$ \\
\hline
\end{tabular}

\section{Subjects and environment}

The subjects of the study were 47 horses employed in sporting activity at different levels: 21 bred through natural boarding (NM) and $26 \mathrm{kept}$ in conventional management (CM) (Table 1). The horses came from 10 teams located in the north of Italy. Each stable was classified as conventional or natural depending on their management and taking into account the parameters specified in Table 2. 


\begin{tabular}{|c|c|c|}
\hline & Conventional Management & $\begin{array}{c}\text { Natural } \\
\text { Management }\end{array}$ \\
\hline $\begin{array}{l}\text { Type of stable buildings and } \\
\text { chance of movement }\end{array}$ & $\begin{array}{l}\text { At least } 18 \mathrm{~h} \text { per day closed in stalls inside the } \\
\text { barn. } \\
\text { Limited daytime dedicated for free movement } \\
\text { and/or equestrian activities ( } 1-6 \text { hours per day). }\end{array}$ & $\begin{array}{l}\text { At least } 12 \text { h per day outside the barn, in } \\
\text { paddocks (minimum criteria: } 20 \mathrm{mt}^{\star} 15 \mathrm{mt} \text { ). } \\
\text { Most of the daytime dedicated for free } \\
\text { movement and equestrian activities. }\end{array}$ \\
\hline Socializing & $\begin{array}{l}\text { Socially isolated in stalls with limited or no } \\
\text { possibilities for social contact with other horses. }\end{array}$ & $\begin{array}{l}\text { High motivation for free socializing with } \\
\text { other horses when in paddocks. }\end{array}$ \\
\hline Feeding & $\begin{array}{l}\text { Feeding } 2 \text { times a day with large volume of hay- } \\
\text { alfalfa hay and high amounts of concentrates. }\end{array}$ & $\begin{array}{l}\text { Feeding ab libitum, or more than } 4 \text { times } \\
\text { a day with grass hay or pasture. }\end{array}$ \\
\hline Thermoregulation & Coat clipped and use of blankets & $\begin{array}{l}\text { Free thermoregulation with no blankets or } \\
\text { clipped coat }\end{array}$ \\
\hline Shoeing & All horses shod & barefoot trimmed \\
\hline Type of bridle & Horses ridden with mouthpieces bridles & Horses ridden without mothpieces. \\
\hline
\end{tabular}

\section{Sample collection}

Sample period lasted from May to July. Blood and horsehair of each animal were sampled once and at the same moment.

Blood sampling from jugular vein was made using one vacutest tube(Kina srl, Arzergrande - ITA) containing lithium-heparin and two vacutest tubes with sodium-EDTA.

Lithium-heparin vacutest tube was kept at room temperature and used for the determination of Blymphocytes and lymphocyte subpopulations CD4+ and CD8+ through flow-cytometry. One sodiumEDTA tube, maintained at room temperature, was used for blood count. Flow-cytometry and blood count were performed within $24 \mathrm{~h}$ from blood collection.

The second sodium-EDTA vacutest tube was centrifuged at $4000 \mathrm{~g}$ for 10 minutes. Plasma was divided into aliquots and immediately frozen at $-20^{\circ} \mathrm{C}$, until radio-immuno-assay (RIA) for the determination of cortisol and DHEA concentration.

Samples of horsehair were taken from the mane, using scissors and they were put in airtight plastic bags. The mane was cut 1-2 $\mathrm{mm}$ from the base, without taking the roots; then the first $3 \mathrm{~cm}$ from the base were used for the analysis.

Each sample was identified and stored at $-20^{\circ} \mathrm{C}$ until RIA for the determination of cortisol and DHEA concentration.

\section{Methods of analysis}

\section{Cortisol and DHEA determination}

Extraction from plasma and horsehair. For the extraction of steroid hormones from plasma, $5 \mathrm{ml}$ of diethyl-ether (BDH Italia, Milan, Italy) were added to $100 \mu 1$ of plasma (Tamanini, Giordano, Chiesa, \& Seren, 1983). Extraction methodology from horsehair was conducted putting $60 \mathrm{mg}$ of trimmed horsehair (1-3 mm) of each sample in a glass vial with $5 \mathrm{ml}$ methanol (Accorsi et al., 2008). All samples were dried under an air-stream suction hood at $37^{\circ} \mathrm{C}$, and the dry-residue was dissolved into phosphate-buffered saline (PBS) 0.05 M, pH 7.5.

Cortisol assay. Cortisol assay in both horsehair and plasma was performed in duplicate, following the method described by Tamanini et al. (1983). The cortisol RIA was performed using an antiserum to cortisol-21-hemisuccinate-BSA, raised in a rabbit, at a working dilution of 1:20 000 and $[3 \mathrm{H}]$-cortisol (amount $30 \mathrm{pg} /$ tube vial) as tracer.

Validation parameters of the analysis were: sensitivity $0.26 \mathrm{pg} / \mathrm{mg}$; intra-assay variability $6.8 \%$; inter-assay variability $9.3 \%$. 
DHEA assay. DHEA was analyzed in horsehair and plasma extracts using a 96-well microtitre plate RIA and a commercial anti-DHEA-7-carboxymethyloxime-BSA (Biogenesis, Poole, UK) that

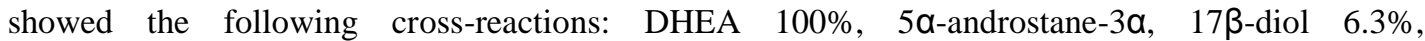
androstenedione $1.3 \%$, testosterone $0.1 \%$, and other related compounds $<0.05 \%$ (Gabai, Marinelli, Simontacchi, \& Bono, 2004). The detection limit of the assay, as calculated by the software Riasmart (Perkin-Elmer Life Sciences), was $1.56 \mathrm{pg} /$ well. The results of the intra- and inter-assay precision test, expressed as coefficients of variation $(\mathrm{CV})$, were $7.4 \%$ and $7.2 \%$, respectively.

Flow cytometry analysis and lymphocytes determination. In order to phenotype lymphocyte subpopulations CD4 +, CD8 + and B cells, 50 $\mu$ l of heparinized blood were mixed with $5 \mu 1$ of the specific antibodies for each surface antigen, in a plastic tube. After $15 \mathrm{~min}$ of incubation in the dark at room temperature, the cells were washed with Phosphate Buffer Solution (PBS)/1\% Fetal Calf Serum (FCS) and centrifuged for 5 min at 400xg. For the CD4+ and CD8+,the cells were then mixed with a secondary antibody and incubated $15 \mathrm{~min}$ in the dark at room temperature, the cells were washed with Phosphate Buffer Solution (PBS)/1\% Fetal Calf Serum (FCS) and centrifuged for 5 min at $400 \mathrm{x}$ g. The contaminating red cells were lysed by treatment with $\mathrm{NH}_{4} \mathrm{Cl}$ solution, $\mathrm{pH} 7.2$, for 15 min at room temperature in the dark. The cell suspension was washed twice with $\mathrm{PBS} / 1 \% \mathrm{FCS}$, centrifuged for $5 \mathrm{~min}$ at $400 \mathrm{x} \mathrm{g}$ and re-suspended in $0.5 \mathrm{ml}$ of PBS/1\%FCS for the flow cytometry analysis (Epics XL-MCL,Colter).

Flow cytometry analysis was performed using mouse anti-horse CD4 (clone CVS4 IgG1 Serotec) and mouse anti-horse CD8 (clone CVS8 IgG1-Serotec) primary antibodies followed by goat anti-mouse IgG1 FITC-labeled secondary antibody (DAKO) and a cross-reacting mouse anti-dog B cells-RPE (clone CA2.1D6 IgG1-Serotec). For each animal unstained cells and cells stained with an irrelevant $\mathrm{mAb}$ were used as negative and isotype controls. Additionally, secondary antibody was checked for unspecific staining by direct secondary antibody incubation for $15 \mathrm{~min}$. Cell gates were set using size (forward scatter, FSC) and complexity (side scatter, SSC) characteristics, and data from at least 10,000 events within the lymphocyte gate were acquired. Dead cells were excluded using 1/1000 Sytox ${ }^{\circledR}$ AAdvanced Dead Cell Stain Kit (Life Technologies), according to the manufacturer's instructions. Blood count with leukocyte formula was performed with the hematology analyzer for multi CELL DYN ® 3500 (Abbott USA Rome, Italy), and B-lymphocytes and lymphocyte subpopulations CD4+ and CD8 + were quantified (Borghetti et al., 2006; Ferrari et al., 2016).

\section{Statistical analysis of data}

The distribution of each variable was evaluated with normality tests of Kolmogorov-Smirnow and Lillefors and W-test of Shapiro-Wilk. In order to highlight significant differences in blood and hormonal parameters between horses bred NM or CM, the ANOVA was performed. Spearman correlation test was used to find a significant correlation between cortisol and DHEA concentrations in plasma and horsehair, and between the other hematological parameters.

To assess the parallelism between standard DHEA and the endogenous hormone, a non-linear regression test was made.

Differences were considered statistically significant for $\mathrm{p}$-value $<0.05$.

Plasmatic and horsehair cortisol/DEHA ratio was calculated. 


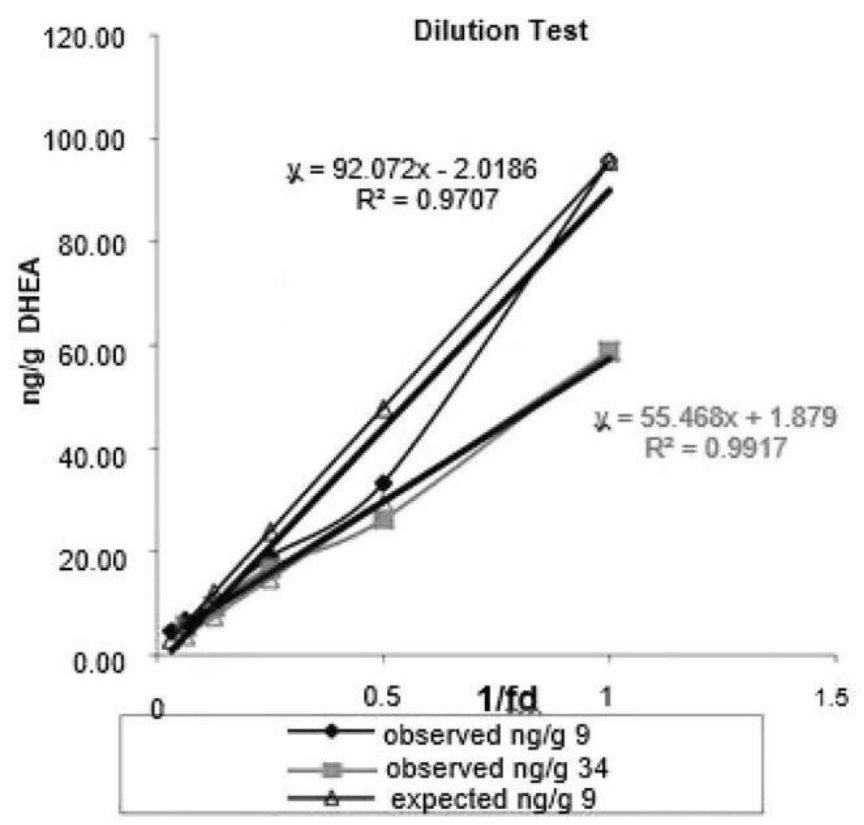

Figure 1. Parallelism between standard DHEA concentration and endogenous DHEA dilutions, using horsehair of research subjects.

Table 3. Mean and standard error (SE) of DEHA and cortisol concentration found in horsehair and plasma of natural horses in two different management conditions. Statistical results are shown (NS = Not Significant).

\begin{tabular}{lccc}
\hline & Natural Boarding & Traditional Management & \\
\cline { 2 - 4 } & Mean \pm SE & Mean \pm SE & p-value \\
\hline $\begin{array}{c}\text { Plasmatic DHEA } \\
(\mathrm{ng} / \mathrm{ml})\end{array}$ & $0.46 \pm 0.03$ & $0.40 \pm 0.03$ & NS \\
$\begin{array}{c}\text { Horsehair DHEA } \\
(\mathrm{pg} / \mathrm{g})\end{array}$ & $30.80 \pm 2.25$ & $16.23 \pm 1.76$ & $<0.001$ \\
$\begin{array}{c}\text { Plasmatic CORTISOL } \\
(\mathrm{ng} / \mathrm{ml})\end{array}$ & $25.71 \pm 1.06$ & $22.07 \pm 1.14$ & NS \\
$\begin{array}{c}\text { Horsehair CORTISOL } \\
(\mathrm{pg} / \mathrm{g})\end{array}$ & $0.16 \pm 0.03$ & $0.76 \pm 0.12$ & 0.003 \\
\hline
\end{tabular}

\section{Results}

\section{Hormonal assay}

It has been found a significant $(\mathrm{p}<0.01)$ parallelism between standard DHEA curve and the endogenous DHEA one, measured using horsehair samples of subjects of the research (Figure 1).

Mean value of DHEA in plasma and horsehair was higher in NM horses rather than in those under CM. Statistical analysis showed that only the difference found in horsehair DHEA concentration between the two groups was significant $(\mathrm{p}<0.001)$. NM subjects registered also a not-significantly higher concentration of plasma cortisol, but they showed a significantly lower $(p=0.003)$ level of horsehair cortisol compared to that of CM horses. All results of hormonal assay are showed in Table 3.

CM horses' plasmatic cortisol/DEHA ratio was 56.92, and a similar value was found in horses kept with a natural management (56.27). However, horsehair cortisol/DEHA ratio was significantly $(\mathrm{p}<0.001)$ higher in traditional (86.46) than natural subjects (23.93) (Figure 2).

Finally, correlations between cortisol and DEHA concentrations found in the two different matrices were evaluated. Negative significant correlations between horsehair cortisol and plasmatic 


\section{Horsehair cortisol/DHEA}

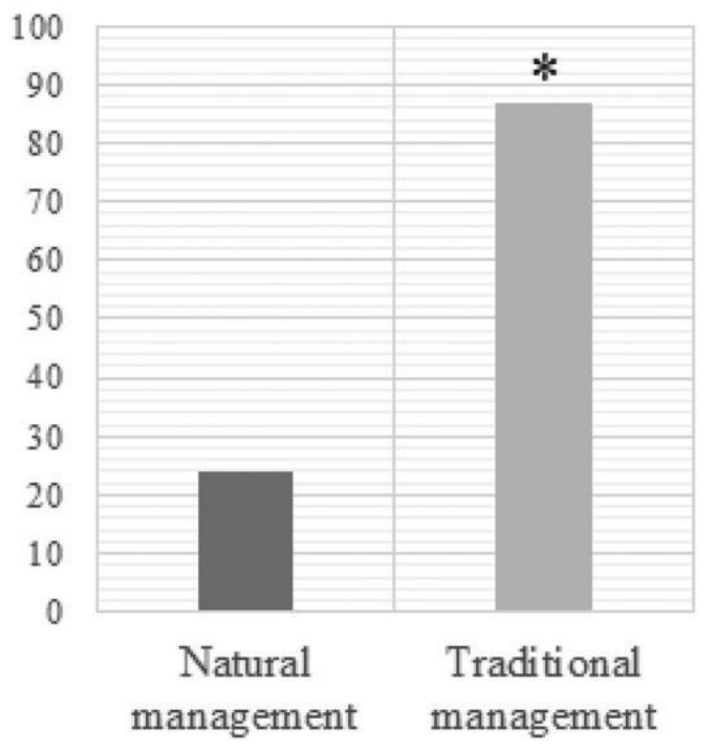

Figure 2. Horsehair cortisol/DHEA ratio in horses with different management. ${ }^{*}=$ statistical significant result.

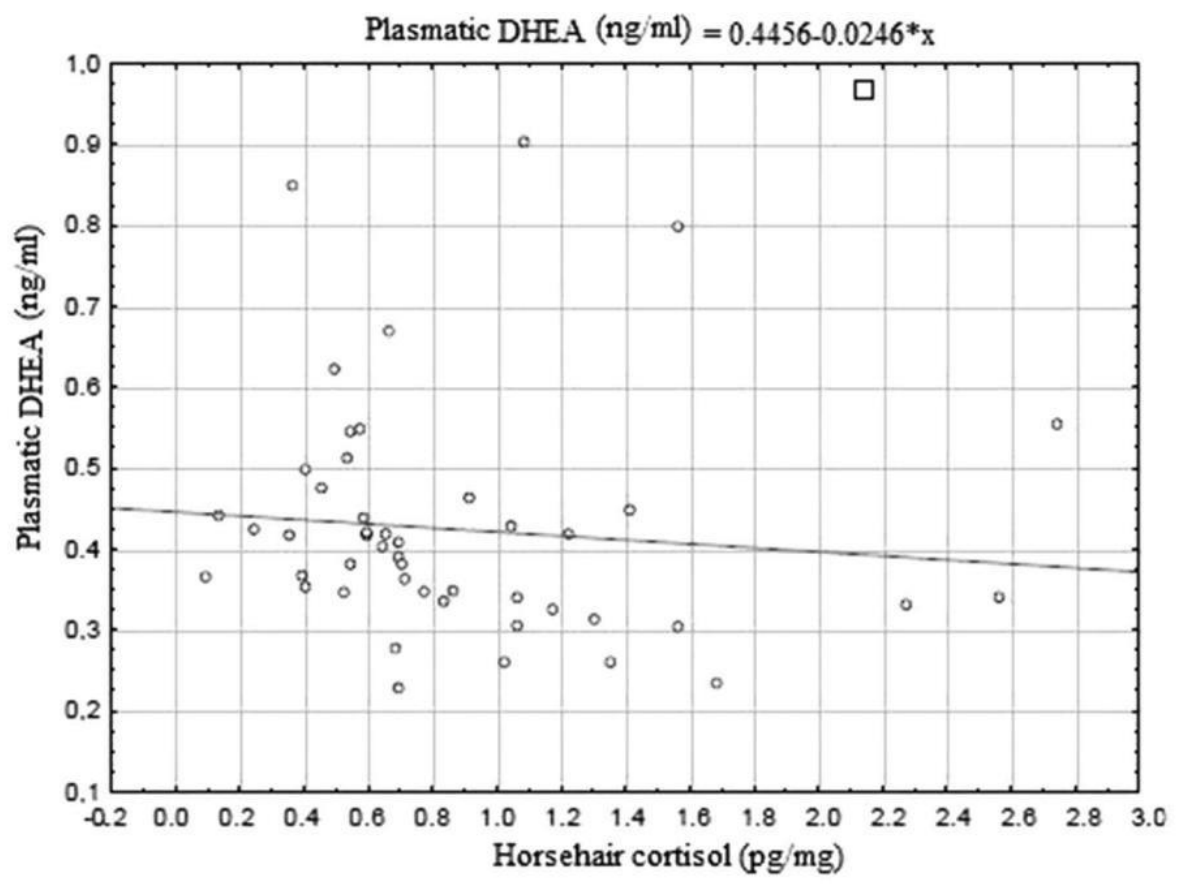

Figure 3. Negative significant correlation between horsehair cortisol concentration $(\mathrm{pg} / \mathrm{mg})$ and plasmatic DHEA levels $(\mathrm{ng} / \mathrm{ml})$.

DHEA $(\mathrm{r}=-0.344, \mathrm{p}=0.018$; Figure 3$)$ and between horsehair cortisol and horsehair DHEA were identified $(r=-0.578, p<0.001$; Figure 4$)$. 


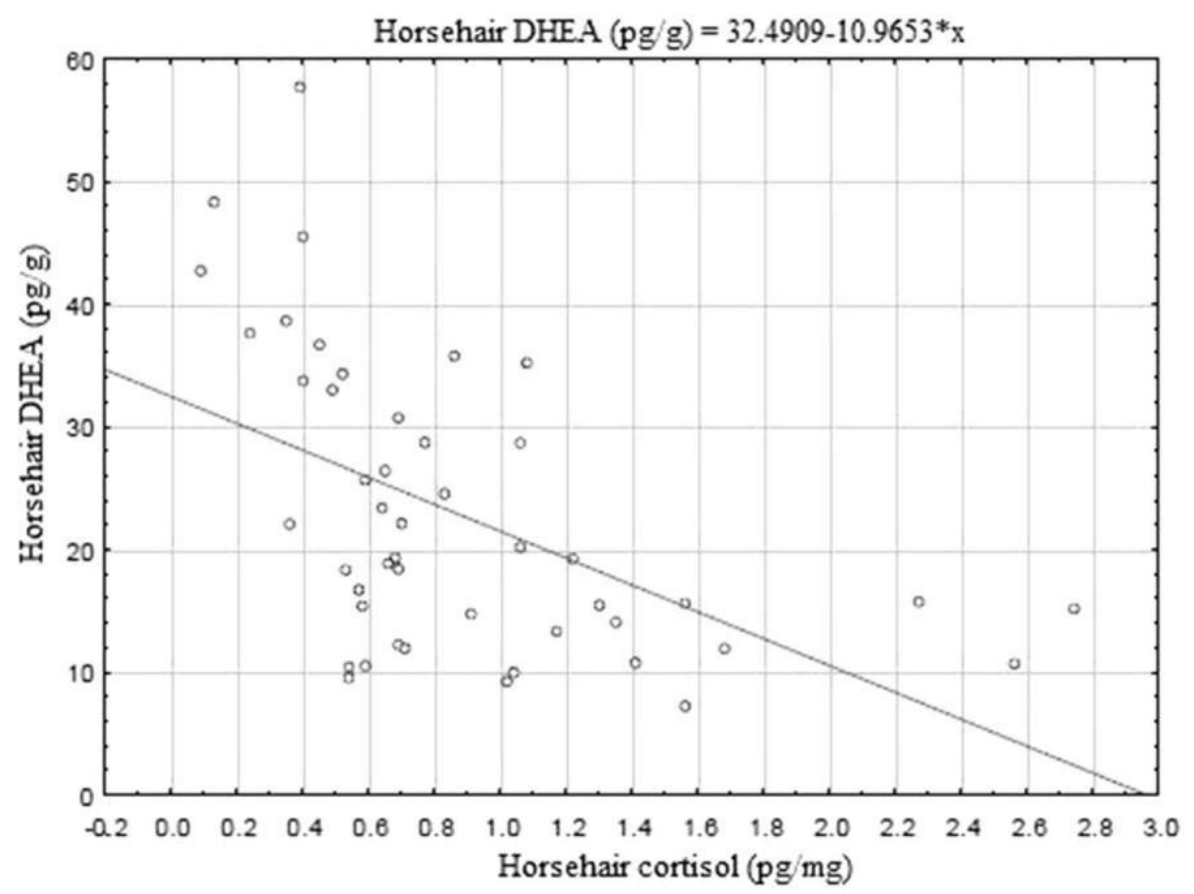

Figure 4. Negative significant correlation between horsehair cortisol concentration (pg/mg) and horsehair DHEA levels (pg/g).

Table 4. Mean and Standard Error (SE) of blood count parameters in the two groups of horses. NS = Not Significant. Hb = hemoglobin; PCV = Packed Cells Volume; RBC = Red Blood Cells; PLTS = Platelets; WBC = White Blood Cells; MCV = Mean Corpuscular Volume; MPV

$=$ Mean Platelet Volume; $\mathrm{MCHC}=$ Mean Corpuscular Hemoglobin Concentration; $\mathrm{MCH}=$ Mean Corpuscular Hemoglobin; RDW = Red cells Dispersion Width.

\begin{tabular}{|c|c|c|c|}
\hline & $\begin{array}{l}\text { Natural } \\
\text { boarding } \\
(n=21)\end{array}$ & $\begin{array}{l}\text { Traditional management } \\
\qquad(\mathrm{n}=26)\end{array}$ & \\
\hline Parameter & Mean \pm SE & Mean \pm SE & $p$-value \\
\hline $\begin{array}{l}\mathrm{Hb} \% \\
\mathrm{PCV} \% \\
\mathrm{RBC} / \mathrm{mm}^{3} \\
\mathrm{PLTS} / \mathrm{mm}^{3}\end{array}$ & $\begin{array}{c}13.46 \pm 0.47 \\
37.32 \pm 1.21 \\
7.79 \times 10^{6} \pm 235,231.69 \\
112.23 \times 10^{3} \pm 7,234.88\end{array}$ & $\begin{array}{c}13.36 \pm 0.69 \\
37.01 \pm 1.75 \\
7.87 \times 10^{6} \pm 423,723.38 \\
115.068 \times 10^{3} \pm 21,213.72\end{array}$ & $\begin{array}{l}\text { NS } \\
\text { NS } \\
\text { NS } \\
\text { NS }\end{array}$ \\
\hline $\mathrm{WBC} / \mathrm{mm}^{3}$ & $6.2 \times 10^{3} \pm 534.69$ & $6.244 \times 10^{3} \pm 393.36$ & NS \\
\hline MCV fL & $47.96 \pm 0.65$ & $47.43 \pm 0.55$ & NS \\
\hline MPV \% & $6.53 \pm 0.37$ & $6.33 \pm 0.36$ & NS \\
\hline $\mathrm{MCHC}$ gr\% & $36.00 \pm 0.13$ & $35.96 \pm 0.18$ & NS \\
\hline $\begin{array}{l}\mathrm{MCH} \text { pgr } \\
\text { RDW \% }\end{array}$ & $\begin{array}{l}17.26 \pm 0.23 \\
24.44 \pm 0.28\end{array}$ & $\begin{array}{l}17.05 \pm 0.19 \\
24.42 \pm 0.48\end{array}$ & $\begin{array}{l}\text { NS } \\
\text { NS }\end{array}$ \\
\hline Lymphocytes $/ \mathrm{mm}^{3}$ & $2.516 \times 10^{3} \pm 184.81$ & $2.299 \times 10^{3} \pm 226.73$ & NS \\
\hline Monocytes $/ \mathrm{mm}^{3}$ & $0.24 \times 10^{3} \pm 39.59$ & $0.24 \times 10^{3} \pm 79.50$ & NS \\
\hline Neutrophils $/ \mathrm{mm}^{3}$ & $4.02 \times 10^{3} \pm 248.18$ & $3.67 \times 10^{3} \pm 213.99$ & NS \\
\hline Eosinophils/mm 3 & $0.237 \times 10^{3} \pm 41.33$ & $0.153 \times 10^{3} \pm 24.81$ & NS \\
\hline Basophiles $/ \mathrm{mm}^{3}$ & $0.118 \times 10^{3} \pm 25.63$ & $0.057 \times 10^{3} \pm 4.98$ & NS \\
\hline
\end{tabular}

\section{Blood parameters}

Considering all the parameters of blood count (Table 4), no statistically significant differences were found between the two groups of horses. However, the mean counts of lymphocytes, neutrophils, basophiles, and eosinophils were higher in NM horses than in CM ones, even if not statistically significant. 
Table 5. Absolute value, percentage, and ratio of lymphocytes subpopulations in the two horses' popula-tions. NS $=$ Not Significant.

\begin{tabular}{|c|c|c|c|}
\hline & $\begin{array}{l}\text { Natural Boarding } \\
(n=21)\end{array}$ & $\begin{array}{l}\text { Traditional Management } \\
\qquad(\mathrm{n}=26)\end{array}$ & \\
\hline Value & Mean \pm SE & Mean \pm SE & $\mathrm{p}$-value \\
\hline CD4+ (\%) & $55.57 \pm 1.55$ & $55.64 \pm 1.36$ & NS \\
\hline CD8+ (\%) & $16.72 \pm 0.70$ & $17.58 \pm 0.77$ & NS \\
\hline $\mathrm{B}(\%)$ & $9.12 \pm 0.63$ & $8.33 \pm 0.44$ & NS \\
\hline CD4/CD8 & $3.45 \pm 0.18$ & $3.32 \pm 0.17$ & NS \\
\hline $\mathrm{CD} 4+/ \mathrm{B}$ & $6.92 \pm 0.65$ & $7.26 \pm 0.50$ & NS \\
\hline CD8+/B & $2.09 \pm 0.22$ & $2.23 \pm 0.14$ & NS \\
\hline CD4+ (n) & $1,386.49 \pm 101.94$ & $1,239.92 \pm 105.22$ & NS \\
\hline CD8+ (n) & $427.84 \pm 40.16$ & $402.91 \pm 40.96$ & NS \\
\hline$B(n)$ & $233.68 \pm 29.22$ & $197.64 \pm 24.93$ & NS \\
\hline
\end{tabular}

Flow cytometry analysis did not show statistically significant differences in lymphocyte subpopulations. The average counts of $\mathrm{B}, \mathrm{CD} 4+$ and $\mathrm{CD} 8+$ lymphocytes were higher in NM subjects; the percentage of B-lymphocytes was higher in NM horses; the percentage of CD8+ lymphocytes were lower in NM horses (Table 5).

\section{Discussion}

This research can be considered innovative for the longitudinal and multidisciplinary approach employed. Hormonal, hematological and immunological parameters have been used to establish sporting horses' condition in two different kind of managements. Moreover, for the first time in this study, DHEA assay method from horsehair has been used and validated.

A standard approach to assess animal stress and welfare is evaluating hypothalamic-pituitaryadrenal (HPA) axis function, measuring levels of glucocorticoids (Mormède et al., 2007). During an acute stress, HPA axis activation and the increasing of plasmatic cortisol level immediately occur. Therefore, plasma is a useful biological matrix to assess acute stress, but often results are altered by blood sampling procedure, which is invasive and stressful for animals (Mormède et al., 2007). In order to evaluate chronic stress, hair sampling can be used. Indeed, cortisol deposits in growing hair, so this kind of sample integrates HPA axis activity over weeks and months and cortisol level is not influenced by acute stress during sampling procedure (Meyer \& Novak, 2012). Cortisol and DHEA have the same precursor: pregnenolone. In human beings, during stressful situation, ACTH (Adrenocorticotropic Hormone) stimulates adrenal cortex to produce cortisol. Therefore, "pregnenolone steal" occurs and cortisol level increase, while DHEA production decrease. As a consequence, cortisol/DHEA ratio increases (Guilliams \& Edwards, 2010).

In this research, horses kept in a natural management showed significantly lower horsehair cortisol level and a significantly higher horsehair DHEA concentration; as a consequence, a significantly lower cortisol/DHEA ratio was observed in NM subjects. Moreover, plasmatic DEHA concentration was higher in NM subjects, even if not significantly. Cortisol concentration in plasma was similar between the two groups, but probably it depended on stress inducted by sampling procedure.

Considering hormonal concentrations as stress index, it may be supposed that natural management allows horses live in less stressful conditions, especially considering long time intervals. Higher levels of cortisol and cortisol/DHEA ratio found in horsehair of CM horses are probably due to a frequent or prolonged activation of the HPA axis.

High DHEA concentration in NM horses could be a positive finding, as this steroid seems to contribute to animal physical health condition and wellbeing. Indeed, DHEA and its sulfated metabolite (DHEAS) would be important as neuroactive steroids in the regulation of neural function, such as neuroprotection, neurogenesis, neuronal growth, and differentiation. Moreover, these hormones would influence catecholamine synthesis and secretion, would have antioxidant and anti-inflammatory action, 
and antagonize glucocorticoid effects (Pluchino et al., 2015). Several studies in humans and animals have demonstrated that neurosteroids could have psychotropic actions. In particular, studies in humans demonstrate that DHEA could have a potential role in the mitigation of stress and could have positive effects on mood symptoms in depressive disorders as antidepressant and on human well-being (Bloch, IshShalom, Greenman, Klein, \& Latzer, 2012; Dor, Marx, Shampine, Rubinow, \& Schmidt, 2015; Russo, Murrough, Han, Charney, \& Nestler, 2012; Maninger, Wolkowitz, Reus, Epel, \& Mellon, 2009).

On the contrary, researches demonstrate that high-prolonged cortisol concentration, detectable by hair analysis, can damage the organism (Stalder \& Kirshbaum, 2012). Cortisol is the principal glucocorticoid hormone; it activates lipolysis and gluconeogenesis, insulin-resistance, increases blood pressure, and modulates the immune system responses (Gow, Thomson, Rieder, Van Uum, \& Koren et al., 2010). Glucocorticoids have both pro-inflammatory and anti-inflammatory action. Initially, in response to an acute stress, glucocorticoids prepare the organism to a quick response and they have a pro-inflammatory action. However, during a chronic or repeated stress, the prolonged high level of glucocorticoids has anti-inflammatory effects and causes immunosuppression of the organism. The tight connection between the endocrine and immune systems makes that a prolonged exposure to stress conditions may lead to the development of inflammatory, autoimmune and allergic diseases (Cruz-Topete \& Cidlowski, 2015; Stalder \& Kirshbaum, 2012). As previously specified, DHEA also influences inflammatory response, and Hilderbrand et al. (2004) demonstrated that in rats this hormone causes the reduction of percentage of CD4+ and CD8+ populations.

The differences in the endocrine milieu between the two groups of horses involved in this research may lead to hypothesize differences also in the blood counts and especially in white cells populations and lymphocytes.

Few studies were performed to analyze the effect of stress on immune parameters in horses; some researches showed that horses exposed to stress can have altered blood parameters, such as Neutrophil/Lymphocyte ratio and macrophage activity, indicating a possible reduction of immune response efficiency (Passatino et al., 2005; Popescu \& Diugan, 2017).

However, we did not find any significant differences between the two groups of horses. Many other factors can influence white cells populations and blood counts (Satuè, Hernandez, \& Muñoz2012), and probably our results depend on the fact that the traditional stables enrolled in this work presented a good standard of management and did not have major deficits that compromise the immune system of animals.

To conclude, results of this research highlight that horses kept under two different kinds of management present different endocrine milieu. Considering the hormonal levels of horses, it can be supposed that CM probably put animals in a chronic stress condition, while the NM seems to comply more with the physiological needs of horses. Conversely, the immune system of animals seemed not to be influenced by the environmental and management conditions. However, the evaluation of cytokine and other inflammatory parameters can help to deepen this topic. Further studies are necessary to complete the assessment of equine welfare in different management conditions, such as behavior evaluation and incidence of diseases.

This study wants to underline the importance of a multidisciplinary approach on the definition of animal condition and the need of scientific research for the improvement of animal management.

\section{Funding}

The study was supported by RFO 60\% Ateneo of Bologna.

\section{ORCID}

G. Marliani (D) http://orcid.org/0000-0002-8609-8349 


\section{References}

Accorsi, P. A., Carloni, E., Valsecchi, P., Viggiani, R., Gamberoni, M., Tamanini, C., \& Seren, E. (2008). Cortisol determination in hair and faeces from domestic cats and dogs. General and Comparative Endocrinology, 155, 398402.

Ayala, I., Martos, N. F., Silvan, G., Gutierrez-Panizo, C., Clavel, J. G., \& Illera, J. C. (2012). Cortisol, adrenocorticotropic hormone, serotonin, adrenaline and noradrenaline serum concentrations in relation to disease and stress in the horse. Research in Veterinary Science, 93(1), 103-107.

Bekoff, M., \& Byers, J. A. (1988). Animal play: Evolutionary, comparative and ecological perspectives. Cambridge: Cambridge University Press.

Bloch, M., Ish-Shalom, S., Greenman, Y., Klein, E., \& Latzer, Y. (2012). Dehydroepiandrosterone treatment effects on weight, bone density, bone metabolism and mood in women suffering from anorexia nervosa-A pilot study. Psychiatry Research, 200, 544-549.

Borghetti, P., De Angelis, E., Saleri, R., Cavalli, V., Cacchioli, A., Corradi, A., .. Martelli, P. (2006). Peripheral T lymphocyte changes in neonatal piglets: Relationship with growth hormone (GH), prolactin (PRL) and cortisol changes. Veterinary Immunology and Immunopathology, 110, 17-25.

Clark, B. J., Prough, R. A., \& Klinge, C. M. (2018). Mechanisms of Action of Dehydroepiandrosterone. Vitamins and Hormones, 108, 29-73.

Cruz-Topete, D., \& Cidlowski, J. A. (2015). One hormone, two actions: Anti- and pro-inflammatory effects of glucocorticoids. Neuroimmunomodulation, 22(1-2), 20-32.

Dor, R. B., Marx, C. E., Shampine, L. J., Rubinow, D. R., \& Schmidt, P. J. (2015). DHEA metabolism to the neurosteroid androsterone: A possible mechanism of DHEA's antidepressant action. Psychopharmacology, 232 (18), 3375-3383.

Ewing, S. A., Lay, J. D. C., \& von Borell, E. (1999). Farm animal well-being. Stress physiology, animal behavior, and environmental design. Upper Saddle River, NJ: Prentice Hall.

Ferrari, L., Borghetti, P., Ferrarini, G., De Angelis, E., Canelli, E., Ogno, G., ... Martelli, P. (2016). Phenotypic modulation of porcine CD14+ monocytes, natural killer/natural killer T cells and CD8 $\alpha \beta+\mathrm{T}$ cell subsets by an antibody-derived killer peptide (KP). Reserch In Veterinary Science, 109, 29-39.

Fraser, D. (2001). The "new perception" of animal agriculture: Legless cows, featherless chickens, and a need for genuine analysis. Journal of Animal Science, 79, 634-641.

Gabai, G., Marinelli, L., Simontacchi, C., \& Bono, G. G. (2004). The increase in plasma C19-delta5 steroids in subcutaneous abdominal and jugular veins of dairy cattle during pregnancy is unrelated to estrogenic activity. Steroids, 69, 121-127.

Goodwin, D. (1999). The importance of ethology in understanding the behaviour of the horse. Equine Veterinary Journal, 28, 15-19.

Gow, R., Thomson, S., Rieder, M., Van Uum, S., \& Koren, G. (2010). An assessment of cortisol analysis in hair and its clinical applications. Forensic Science International, 196, 32-37.

Guilliams, T. G., \& Edwards, L. (2010). Chronic stress and the HPA axis: Clinical assessment and therapeutic considerations. The Standard, 9(2), 1-12.

Hilderbrand, F., Pape, H. C., Harwood, P., Wittwer, T., Krettek, C., \& Van Griensven, M. (2004). Are alterations of lymphocyte subpopulations in polymicrobial sepsis and DHEA treatment mediated by the tumor necrosis factor (TNF)-alfa receptor (TNF-RI)? A study in TNF-RI (TNF-RI-/-) knock-out rodents. Clinical \& Experimental Immunology, 138, 221-229.

Hill, M., Dušková, M., \& Stárka, L. (2015). Dehydroepiandrosterone, its metabolites and ion channels. Journal of Steroid Biochemistry and Molecular Biology, 145, 293-314.

Maninger, N., Wolkowitz, O. M., Reus, V. I., Epel, E. S., \& Mellon, S. H. (2009). Neurobiological and neuropsychiatric effects of dehydroepiandrosterone (DHEA) and DHEA sulfate (DHEAS). Frontiers in Neuroendocrinology, 30, 65-91.

Meyer, J. S., \& Novak, M. A. (2012). Minireview: Hair cortisol: A novel biomarker of hypothalamic-pituitaryadrenocortical activity. Endocrinology, 153(9), 4120-4127.

Mills, D., \& Nankervis, K. (2001). Comportamento equino. Principi e Pratica (1 ed.). Bologna: Calderini, Edagricole.

Moberg, G. P. (1987). A model for assessing the impact of behavioural stress on domestic animals. Journal of Animal Science, M65, 1228-1235.

Moberg, G. P. (2000). Biological response to stress: Implications for animal welfare. In G. P. Moberg \& J. A. Mench (Eds.), The biology of animal stress (pp. 1-21). Wallingford: CAB International.

Mormède, P., Andanson, S., Aupérin, B., Beerda, B., Guémené, D., Malmkvist, J., ... Veissier, I. (2007). Review: Exploration of the hypothalamic-Pituitary-Adrenal function as a tool to evaluate animal welfare. Physiology \& Behavior, 92, 317-339.

Padgett, D. A., \& Glaser, R. (2003). How stress influences the immune response. Trends in Immunology, 24(8), 444448. 
Passantino, L., Amati, L., Cianciotta, A., Passantino, G., Perillo, A., Ribaud, M. R., ... Jirillo, E. (2005). Modifications of serum and cellular parameters in trotters after a race. Macrophage migration inhibitory activity reduction and serum beta-glucan elevation. Immunopharmacology and Immunotoxicology, 27(2), 299-314.

Pluchino, N., Drakopoulosa, P., Bianchi-Demichelia, F., Wengera, J. M., Petignata, P., \& Genazzani, A. R. (2015). Neurobiology of DHEA and effects on sexuality, mood and cognition. The Journal of Steroid Biochemistry and Molecular Biology, 145, 273-280.

Popescu, S., \& Diugan, E. A. (2017). The relationship between the welfare quality and stress index in working and breeding horses. Research in Veterinary Science, 115, 442-450.

Prall, S. P., \& Muehlenbein, M. P. (2018). DHEA modulates immune function: A review of evidence. Vitamins and Hormones, 108, 125-144.

Russo, S. J., Murrough, J. W., Han, M., Charney, D. S., \& Nestler, E. J. (2012). Neurobiology of resilience. Nature Neuroscience, $15,1475-1484$.

Saba, C., Montagnani, A., \& Ascione, L. (2014). Guida pratica alla Gestione Naturale del Cavallo. Fivizzano, MS: Equiluna asd.

Silverman, M. N., \& Sternberg, E. M. (2012). Glucocorticoid regulation of inflammation and its functional correlates: From HPA axis to glucocorticoid receptor dysfunction. Annals of the New York Academy of Sciences, 1261, 55-63.

Stalder, T., \& Kirshbaum, C. (2012). Analysis of cortisol in hair - State of the art and future directions. Brain, Behavior, and Immunity, 26, 1019-1029.

Strasser, H. (2005). Dalla salute dello zoccolo al benessere del cavallo. Iesa, SI: Equitare.

Tamanini, C., Giordano, N., Chiesa, F., \& Seren, E. (1983). Plasma cortisol variations induced in the stallion by mating. Acta Endocrinologica, 102, 447-450.

Van Dierendonck, M. C., \& Goodwin, D. (2005). Social contact in horses: Implications for human-horse interactions. In F. De Jonge \& R. van Den Bos (Eds.), The Human-Animal relationship: Forever and a day (pp. 65-82). Assen, The Netherlands: Royal Van Gorcum BV.

Veissier, I., \& Boissy, A. (2007). Review: Stress and welfare: Two complementary concepts that are intrinsically related to the animal's point of view. Physiology \& Behavior, 92, 429-433. 